\title{
Informe y Aciclopedia. Dos dispositivos de creación y pensamiento en torno al canon de la forma
}

\author{
Dr. Cristián Gómez-Moya \\ Universidad de Chile \\ deform.cgm@gmail.com
}

\begin{abstract}
Resumen
El artículo expone una discusión en torno al canon de la forma predominante en las prácticas de creación contemporánea y utiliza como referente un proyecto académico realizado en la Facultad de Arquitectura y Urbanismo de la Universidad de Chile. En este caso, se abordan dos de los dispositivos diseñados durante el desarrollo de dicho proyecto: una cápsula (Informe) y una publicación (Aciclopedia), los cuales operaron como intertextos del mismo problema. De este modo, se busca explicitar las condiciones de investigación-creación que animaron algunas de las cuestiones acerca de la forma; como categoría asociada a la genealogía enciclopédica del "informe": la burocracia letrada, por un lado, y lo que carece de forma, por el otro.
\end{abstract}

\section{Palabras clave}

Forma; informe; sin forma; enciclopedia; dispositivo.

\section{Informe e Aciclopedia. Dois dispositivos de criação e pensamento em torno} do cânone da forma.

\section{Resumo}

O artigo expõe uma discussão sobre o cânone da forma predominante nas práticas de criação contemporânea, e utiliza como referente um projeto acadêmico realizado na Faculdade de Arquitetura e Urbanismo da Universidade do Chile. Neste caso, dois dos dispositivos projetados durante o desenvolvimento do referido projeto são abordados: uma cápsula (Informe) e uma publicação (Aciclopedia), que funcionavam como intertextos do mesmo problema. Desta maneira, procuramos explicar as condições de criação da pesquisa que animaram algumas das questões sobre a forma; como uma categoria associada à genealogia enciclopédica do "relato": como uma burocracia alfabetizada, por um lado, e que carece de forma, por outro.

\section{Palavras chaves}

Forma; relatório; sem forma; enciclopédia; dispositivo.

\section{Informe and Aciclopedia. Two devices of creation and thought for the ca- non of the form.}

\footnotetext{
Abstract

The article presents a discussion about the canon of form which has predominated in the practices of contemporary creation, taking the example of an academic project carried out by the Faculty of Architecture and Urbanism at the University of Chile. In this case, two devices were designed during the development of said project: a
} 
bulletin (Informe) and a publication (Aciclopedia), which operated as intertexts of the same problem. We seek to specify the conditions of research-creation that inspired some of the questions about form as a category associated with the encyclopedic genealogy of the word informe ("report" or "formless"). This will be explored in terms of the cultured bureaucracy, on the one hand, and what has no form (formless), on the other.

\section{Keywords}

Form; report; formless; encyclopedia; device. 


\section{Introducción}

El propósito de este artículo es problematizar la noción de "forma", cuya simple expresión se ha vuelto propia de aquellos campos de conocimiento que giran en torno a las artes, la arquitectura y el diseño, por nombrar algunos. En estas tradiciones podemos reconocer diferentes dimensiones: desde la división platónica entre mundo sensible y habitar de las ideas, sumado al devenir de las sombras; pasando por el germen de la forma como misterioso fetiche de la mercancía capitalista, la gute-form, que se ofreció como paradigma trascendental de una nueva vida (new living) centrado en una gestáltica tardía durante las escuelas proyectuales de postguerra europeas; hasta el predominio del funcionalismo en la segunda mitad del siglo veinte, lo que terminó desplazándose hacia nuevos problemas debido a la misma desmaterialización de la forma en los actuales contextos postcapitalistas a nivel global. Sin embargo, es también atendible que la propia naturaleza de la categoría en cuestión comprenda otra genealogía bifurcada a propósito del prefijo in: el informe, en tanto reporte, noticia y documentación perteneciente al campo del enciclopedismo, y lo informe, en consonancia con lo que no tiene forma.

Así, teniendo a la vista este último diferendo sobre la categoría de la forma, este artículo explora sucintamente algunas de las discusiones en torno a ello, particularmente las que atravesaron el proyecto Informe. Dispositivo de activación y experimentación de un no-espacio, realizado en la Facultad de Arquitectura y Urbanismo de la Universidad de Chile en $2016^{1}$, cuyo programa se materializó por medio de dos dispositivos de creación y pensamiento: una cápsula y una publicación. El primero consistió en la creación, arquitectura y diseño de una plataforma curatorial que, bajo el título Informe ${ }^{2}$, tuvo como propósito la activación de una zona en desuso para establecer relaciones intersticiales sobre la forma y el espacio; el segundo se desarrolló por medio de un ejercicio editorial, como paratexto del primero, en el que se convocó a distintos escritores y artistas a problematizar el canon de la forma a través de un pequeño breviario denominado Aciclopedia ${ }^{3}$.

Sin ánimo de describir o dar mera noticia de las cualidades técnicas y disciplinares de ambos ejercicios -ya que de ese modo se neutralizaría el sentido que esta misma publicación periódica promueve, en orden a revisar prácticas transdisci-

\footnotetext{
1 El proyecto fue desarrollado como investigación y obra de creación artística, obteniendo el Fondo CreArt 2015-2016 (CA 04/15), de la Dirección de Creación Artística (DiCREA), Vicerrectoría de Investigación y Desarrollo (VID), Universidad de Chile. Los responsables fueron, Cristián Gómez-Moya, Diego Gómez Venegas, Mario Marchant Lannefranque y Daniel Opazo Ortiz, académicos pertenecientes a los Departamentos de Arquitectura y Diseño de la Facultad de Arquitectura y Urbanismo, Universidad de Chile. El diseño de la cápsula se desarrolló en conjunto con la oficina Arqtex, mientras el diseño editorial correspondió a cgm+elissetche|estudio.

2 Documentación asociada al proyecto se encuentra en el sitio web http://informe.uchilefau.cl/.

3 El libro, en versión PDF, ha sido liberado bajo una licencia Creative Commons y se puede descargar de la página web http://informe.uchilefau.cl/aciclopedia/.
} 
plinarias desarrolladas en contextos de procesos creativos-, en este artículo se exponen algunos de los fundamentos teóricos, así como los aspectos discursivos, creativos y curatoriales que dieron impulso al proyecto y lo atravesaron -no sin pocas dificultades administrativas- a lo largo de su itinerario. Al mismo tiempo, se busca documentar visualmente algunos de sus resultados, de manera de posibilitar un intertexto que permita, a través de las mismas referencias utilizadas en el proyecto, dar continuidad a los problemas ahí planteados; sin traicionar, por cierto, el sentido crítico de su propia matriz de pensamiento.

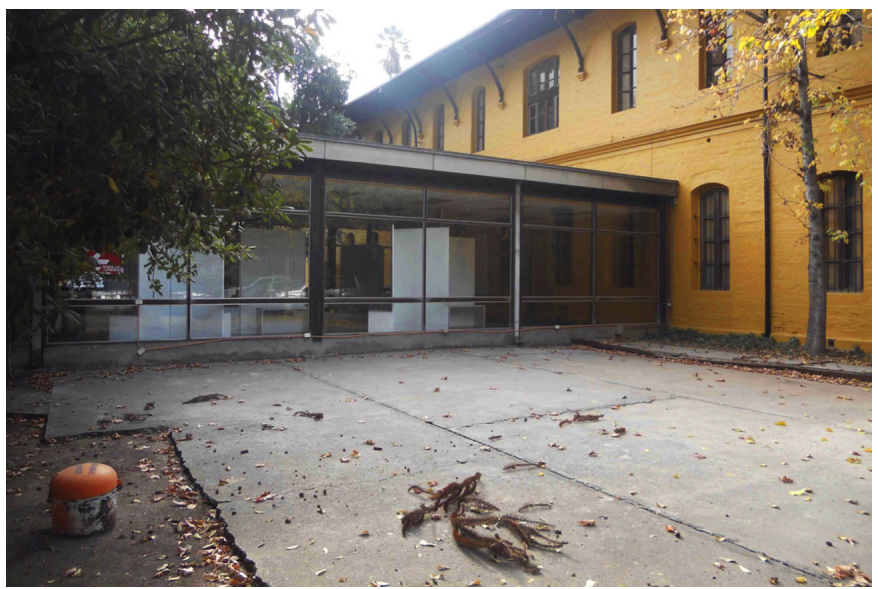

Registro de un no-espacio. Vista interior en FAU/U. de Chile, 2016. Fotografía equipo curatorial.

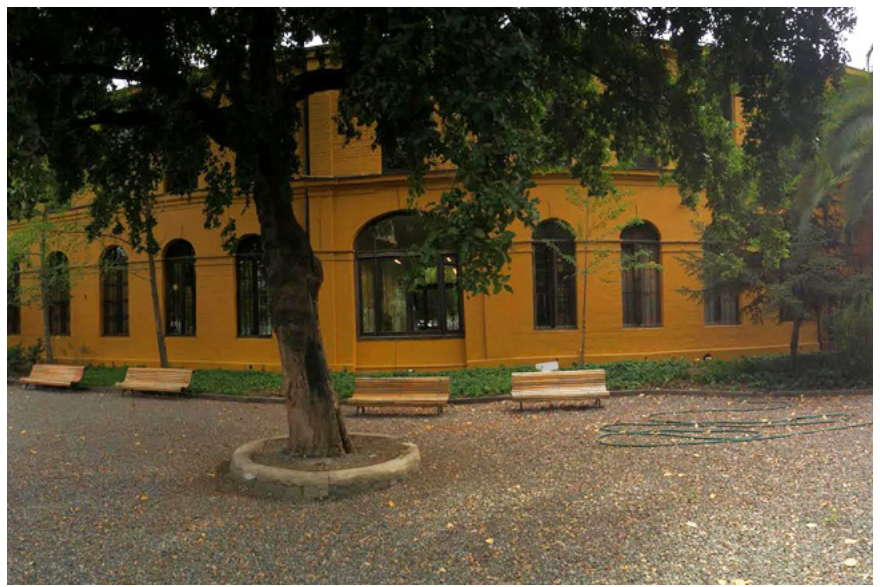

Vista interior en FAU/U. de Chile, 2016.

Fotografía equipo curatorial. 


\section{Informe}

Bajo la genealogía de cierta tradición logocentrista heredada por las disciplinas humanistas y artísticas, las que además se vieron fortalecidas por la ontología de un saber marcado por la téchne -en tanto saber dominante bajo aquella escritura heideggeriana que interrogó el misterio de la técnica-, es posible reconocer el estructuralismo binario de la forma en tanto apariencia, por un lado, y función, por el otro. Forma, sin embargo, que al mismo tiempo no es primera, sino que está precedida por una antinomia que la determina y cuya fuerza pasa por la escritura ${ }^{4}$; esto es, por la escritura de lo que informa. Sabemos, en este sentido, y sin pretender establecer una cronotopía de ambas nociones, que tanto la escritura -ya sea bajo el sentido de lo indicial y su campo de aplicación (grafía)-, como la forma -en virtud de lo que aparece y su contorno (morpha)-, operan en cualquier caso como ordenamientos verosímiles en oposición a la materia y la sustancia.

De ahí que la razón logocéntrica acumulada en hojas impresas mediante un índex alfabético de letras o imágenes sirva para comprender la vitalidad de un conocimiento humanista para la ley del informe -aquello que bien podemos reconocer como su propio origen situado en el archivo (arkhé). Cabe subrayar, por ejemplo, la peculiar raíz latina de la palabra informe, puesto que incluye el prefijo in, alusivo a aquello que en su interior tiene forma (en). De este modo, el informe consiste en reflejar desde fuera hacia dentro, es decir, dar noticia de la forma interna de algo desde el exterior. En este sentido, por tanto, es la carpeta que recubre aquello que, sin ser visto, sabemos que se mantiene adentro. Una portada o portadilla que no es la forma en sí- confiere entonces algo de lo que esperamos ver -no sin poca ansiedad o nerviosismo frente a lo incierto de una desnudez corpórea que sólo podemos imaginar- de su forma dentro ${ }^{5}$. Por otro lado, lo informe también comparece como irregular, sin forma, deforme; cuestión que niega la forma -negatividad (ne) en el prefijo griego a, an (amorfo, apatía / anomia, anarquía)- y hace de ella algo que no será dado a ver. Su forma negada es propia, entonces, de una falta de norma (anomia) en el orden de lo que gobierna o bien de su anarquía. Es este otro prefijo, $a$, el que niega, por tanto, cualquier forma ${ }^{6}$.

Habida cuenta de ello, la ley de un informe humanista sería, en contra de la acepción de la anomia, la ley de lo que sí puede ser visto como la superficie de la

\footnotetext{
4 Nos referimos a un ejercicio crítico que no adscribe necesariamente a la tesitura sobre la debacle de la escritura como historia de lo humano, sino que se pregunta por la verdadera tensión provocada por el debate humanismo-posthumanismo que concitó una historia de las máquinas; debate que, en el último tiempo, se ha concentrado en las relaciones entre diseño, humanismo y pensamiento, según lo evidencian autores como Latour \& Weibel (2005) o los casos más recientes de la 3rd Istanbul Design Biennial (2016) y la plataforma editorial online Superhumanity (2016-2017).

5 Dar vuelta la piel de un cuerpo dejando a la vista sus entrañas. Ver, entre otros, los estudios de Andreas Vesalius, De Humani Corporis Fabrica (1543).

6 Este prefijo será retomado en el análisis del segundo dispositivo.
} 
forma o, mejor, como la superficie-carpeta que informa de aquello que ahí subyace. Habitualmente, estas carpetas se acumulan detrás de la burocracia (bureau, cabinet, archive), una que requiere del mobiliario para revisión de volúmenes y que, a pesar de su abarrotamiento, contiene las formas que guardan sus informes; sus estados del arte o las experiencias perdidas del arte (Spieker, 2008). El krátos de la buro-cracia instala el poder detrás de un buen escritorio (bureau). En parte, esta expresión se vuelve imponente respecto del exceso y la gobernabilidad sostenida por la mirada severa de quien cautela la mensura del tiempo, así como el orden latente en cada renglón todavía vacío. Además, cabe en la burocracia el ejercicio performático de quien la ejerce como secretario, el cual muchas veces opera, en su doble agencia, también como testigo; de modo de atestiguar la falta e informar oportunamente de un saber qué hacer.

A reserva de su efecto vigilante, la burocracia contemporánea no es algo indeseable, toda vez que se atisba la posibilidad del daño, aquello que Jacques Rancière identifica, precisamente, bajo el requerimiento de la policía. Todo lo político, dice el filósofo (2000: 146), requiere manejar el daño; esto es, producir las distinciones entre régimen estético (la política) y régimen representativo (la policía). Para decirlo de una manera ciertamente enrevesada, pero ineludible: lo político es, para el filósofo, el interregno entre la política (la idea de igualdad) y la policía (el gobierno que organiza la comunidad). Lo político, entonces, corresponde a la interfaz, es decir, a lo que se da entre la política y la policía. No obstante, tal como él mismo observa en su célebre artículo "Política, identificación y subjetivación": "toda policía hace daño a la igualdad [a la política]" (2000: 146). Por lo tanto, lo político se hace cargo del tratamiento de un daño; el daño ejercido contra una comunidad en estado de igualdad.

En consecuencia, la burocracia de los informes -lo que garantiza la política de la igualdad- puede ser dañada por la policía, si esta ve en los informes un régimen de representación único: "La policía dice que no hay nada que mirar. Dice que el espacio de circulación es sólo el espacio de circulación" (Rancière, 2006: 71). Un ejercicio desde lo político, en cambio, permite hacer ver el daño de esa descomunal forma de burocracia que rompe la igualdad, por ello, tal como lo expone el filósofo, "la política consiste en transformar este espacio de circulación en espacio de manifestación de un sujeto" (72).

Si lo político ha quedado entre la política y la policía; si en un informe subyace la aspiración administrativa que controla la igualdad, no es inverosímil, por tanto, advertir la dimensión policial que siempre hay detrás de la forma. Es más, si todo informe es parte de una obra que se alinea con la cuestión de la forma, es consustancial a toda obra, entonces, trabajar con la burocracia. Y es así puesto que la forma es en sí misma una cuestión burocrática -"una cuestión formal", se dice-, en fin, una cuestión policial. 


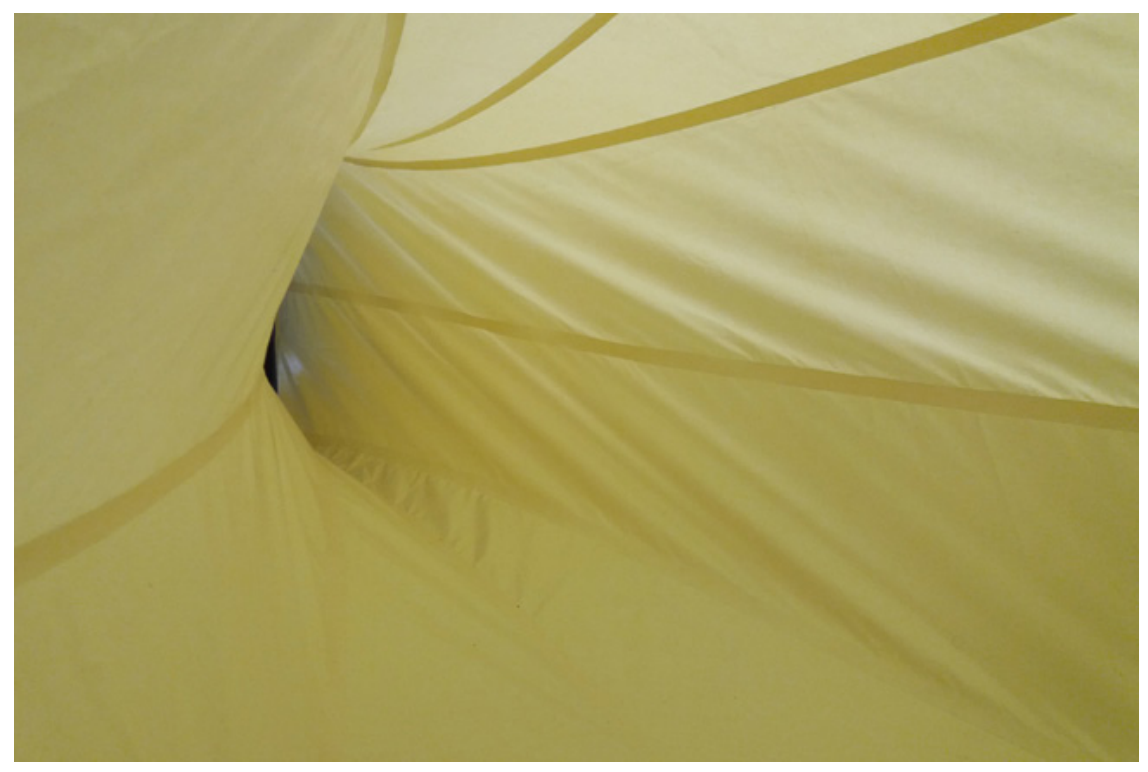

Informe, vista interior de cápsula en FAU/U. de Chile, 2016. Fotografía equipo curatorial.

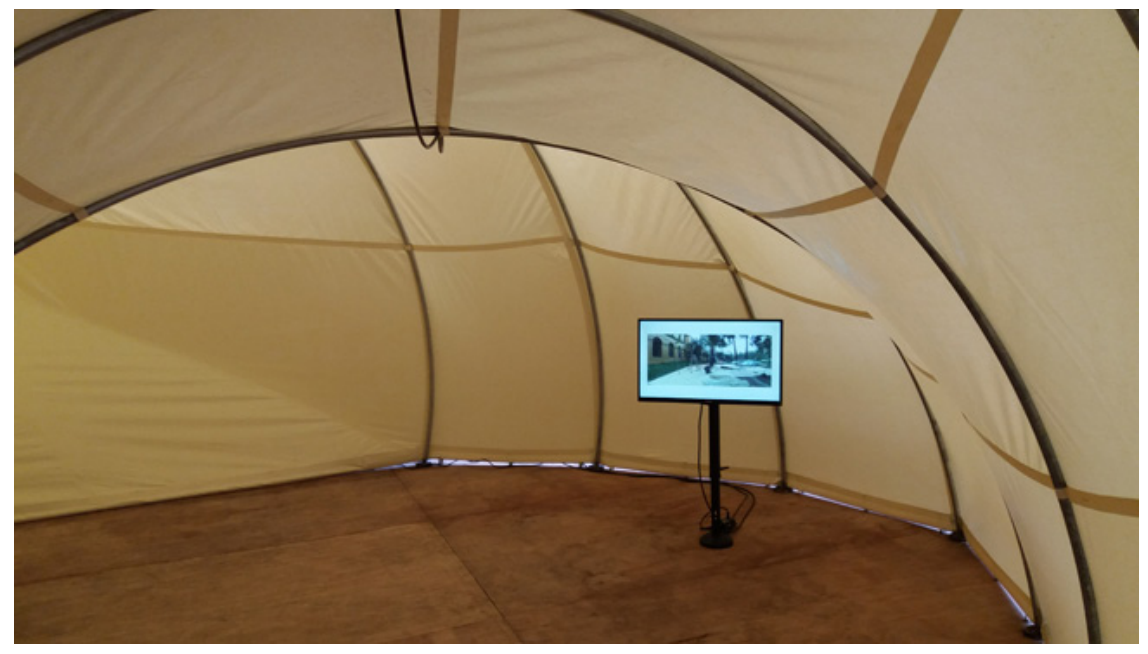

Informe, vista interior de cápsula en FAU/U. de Chile, 2016. Fotografía equipo curatorial. 


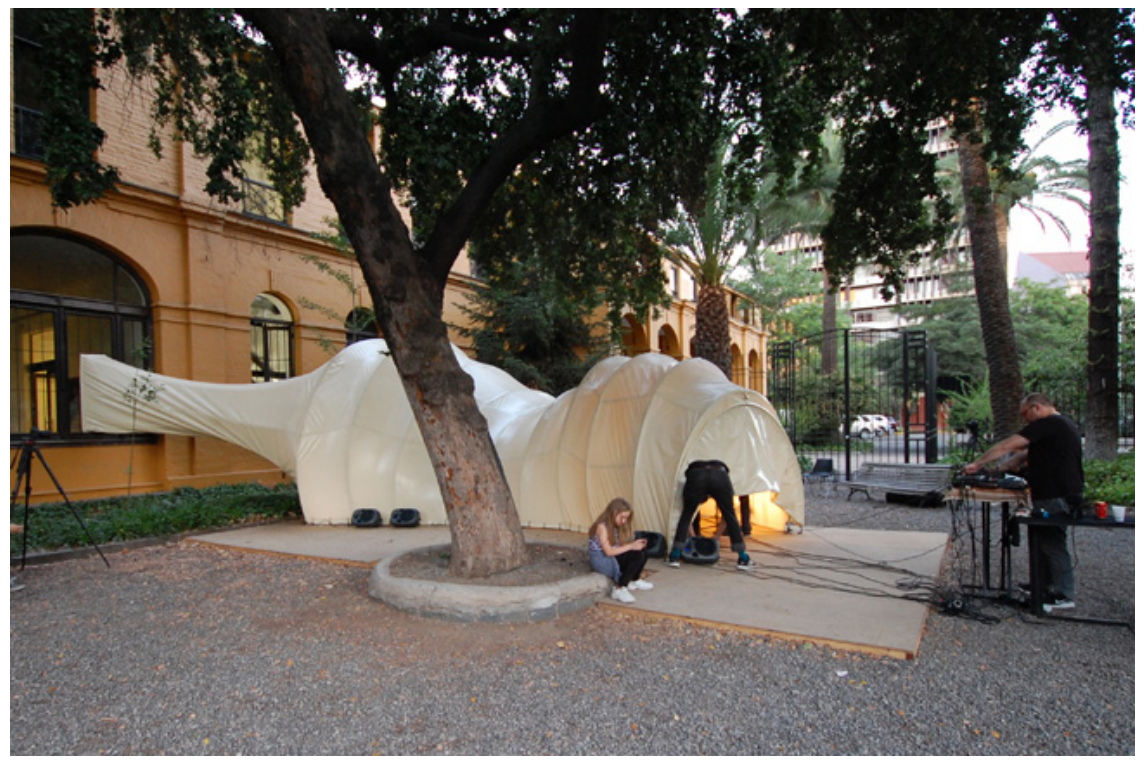

Informe, vista exterior de cápsula en FAU/U. de Chile, 2016.

Fotografía equipo curatorial.

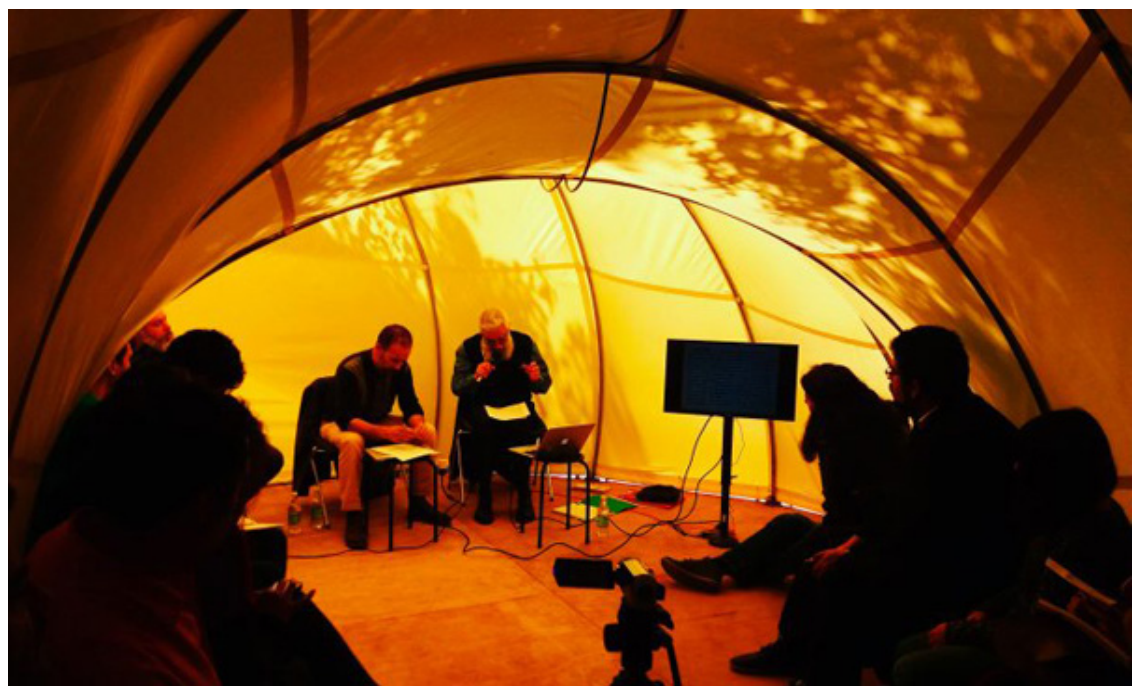

Seminario-reader "Lo informe y el canon", Pablo Rivera y Hugo Rivera-Scott. Informe, vista interior de cápsula en FAU/U. de Chile, 2016.

Fotografía equipo curatorial. 


\section{Cápsula}

Contenida bajo la forma de la burocracia, la cápsula Informe buscó aproximarse a una idea de lo político en el espacio de circulación. Se trató de una forma parasitaria, ya que la construcción de su aparato estructural se conectó a la energía que le proveía su propia administración (decanatus) dentro de la Facultad -se acopló para dar cuenta de lo que sucedía en el interior de un organismo. Así, haciendo uso de una metáfora de las formalidades, esta cápsula Informe fue facultada -no sin antes mediar una extensa serie de cartas de autorización allegadas a la burocracia para habilitar su propia condición de informe; lo que es ya una aparente tautología-, de manera de proceder a completar su objetivo en un espacio en desuso de la institución académica. Básicamente, este objetivo era el de emancipar a la burocracia misma por medio de voces y cuerpos que, en su interior-exterior, hicieran posible la desidentificación del espacio.

Dicha energía parasitaria, a pesar de su indeseada adscripción a la gramática de la administración, compartió los bordes de una burocracia con el propósito de ocupar sus propios intersticios. Es relevante, por ello, pensar la forma no sólo a través de la apariencia de un cuerpo reconocible o por reconocer, sino a través de la problemática ocasionada por la dimensión del entre, es decir, de aquello que se da y lo que queda en medio de otras formas en sí ya percibidas o reconocidas. Justamente, nos referimos a una preposición que "denota aquello que tiene lugar al medio de dos o más cosas" (Thayer, 2016: 26), aunque también podemos afirmar que, si el entre dirime o satura ese lugar intermedio, eso no significa que posea forma; no obstante, y bajo el mismo raciocinio, tampoco podríamos afirmar que carece de ella a perpetuidad. Esa es la incógnita política de lo que Rancière, por su parte, ha denominado el entremedio (in-between) (2000: 151). Y así, del mismo modo que la intersección carece de un centro estable o que "[c]ada época rueda hacia un determinado imaginario de la X" (Flores, 2016: 106), el lugar del entre es la posibilidad de imaginar el porvenir de la forma en una disposición cruzada, precisamente en el quiasmo: la forma del entre o el entre de la forma.

Otra de las premisas de la cápsula Informe fue su instalación como un todavía no de la forma. Incluso, al inicio, se habló de un no-espacio -una condición diferente a ese "no-lugar" de la sobremodernidad identificado con las instalaciones y los medios de tránsito en que las personas se volvían simples pasajeros o bien con los campos de tránsito para el estacionamiento de refugiados (Augé, 2002: 41). Es por ello que hace falta precisar el tiempo de este espacio en virtud de su prefijo, 
esto es, el "no" que impide su habitabilidad y su habilitación. Es un no-espacio porque su espacialidad está negada de antemano -ello se sabe, se antecede que no es apto, que está cerrado a la circulación- y ésta se niega porque el espacio es negado en sí mismo, en su propia apariencia que se deja ver como si careciera de uso, contemplación y representación: como ajeno a toda ética. Pero esto sólo lo sabemos una vez que es solicitado; es igual, se confirma la negatividad porque el "no" constituye en sí una falta de cosa: no es una cosa y, al no serla, tampoco es una forma. Su existencia únicamente depende de su negatividad y, en consecuencia, su devenir se vuelve necio, nulo, nimio, nefasto. Es ésta, sin embargo, una negativa que oficia de productiva jurisdicción; mientras no sea un espacio, una cosa, una forma, será una mera representación policial.

Ahora bien, ¿cómo hacer de este espacio una acción que, sin reconocer su forma o sin buscar nombrarla (cápsula, gusano, tímpano), acontezca como lugar del entre? El modo de su posibilidad fue -como si ella pensara por sí misma- la (in) habitabilidad de sus perímetros, así como la (des)ocupación de sus intersticios. De un modo que finalmente no hizo más que dar cuenta de su extrañeza en el lugar de consignación, esta cápsula Informe ofició de parásito sin memoria, como una gusaneidad carente de patrimonio propio ${ }^{7}$, es decir, como una forma sin anhelo de preservación, pero además desprovista de centro, entrada o salida, como una extensión tubular a través de la cual desplazarse sin dejar rastro de ello. Así, la transitoria vida orgánica de esta forma se produjo sin más preservación que el acontecimiento parlante, aquel que cada cierto tiempo agenció a un grupo de escritores, artistas y docentes bajo la sintaxis de una lectura (Pablo Rivera, Hugo Rivera-Scott, Ángela Ramírez, Ignacio Szmulewicz, José Solís, Rodrigo Tisi, Román Domínguez) o de un acto multimedial heteróclito (Daniel Cruz, Claudia González, Bernardo Piñero, Gerardo Della Vecchia, Martín Gubbins, Felipe Cussen) $)^{8}$. Así, esta cápsula se hizo eco de aquella antigua noción desclasificada por Bataille -apostilla no homologada y en ningún caso consensuada por el universo académico- que la forma no se parece a nada y siempre puede ser algo así como una araña o un escupitajo (Bataille, 1929: 382).

\footnotetext{
Al respecto recuperamos la noción flusseriana utilizada por Baitello (2017), para reflexionar sobre el consumo en el campo de los medios y la industria; básicamente para señalar aquello que no tiene memoria de lo que ha comido ni de lo que ha excretado, es todo lo mismo.

8 Los curadores del proyecto realizaron invitaciones a diversos artistas y escritores a plantear encuentros, lecturas y acciones en torno a la cápsula Informe. Los aquí nombrados accedieron a intervenir activamente en función del proyecto, propiciando con ello una forma de academia periférica y descentrada de la convención asociada al relato educativo-normativo.
} 

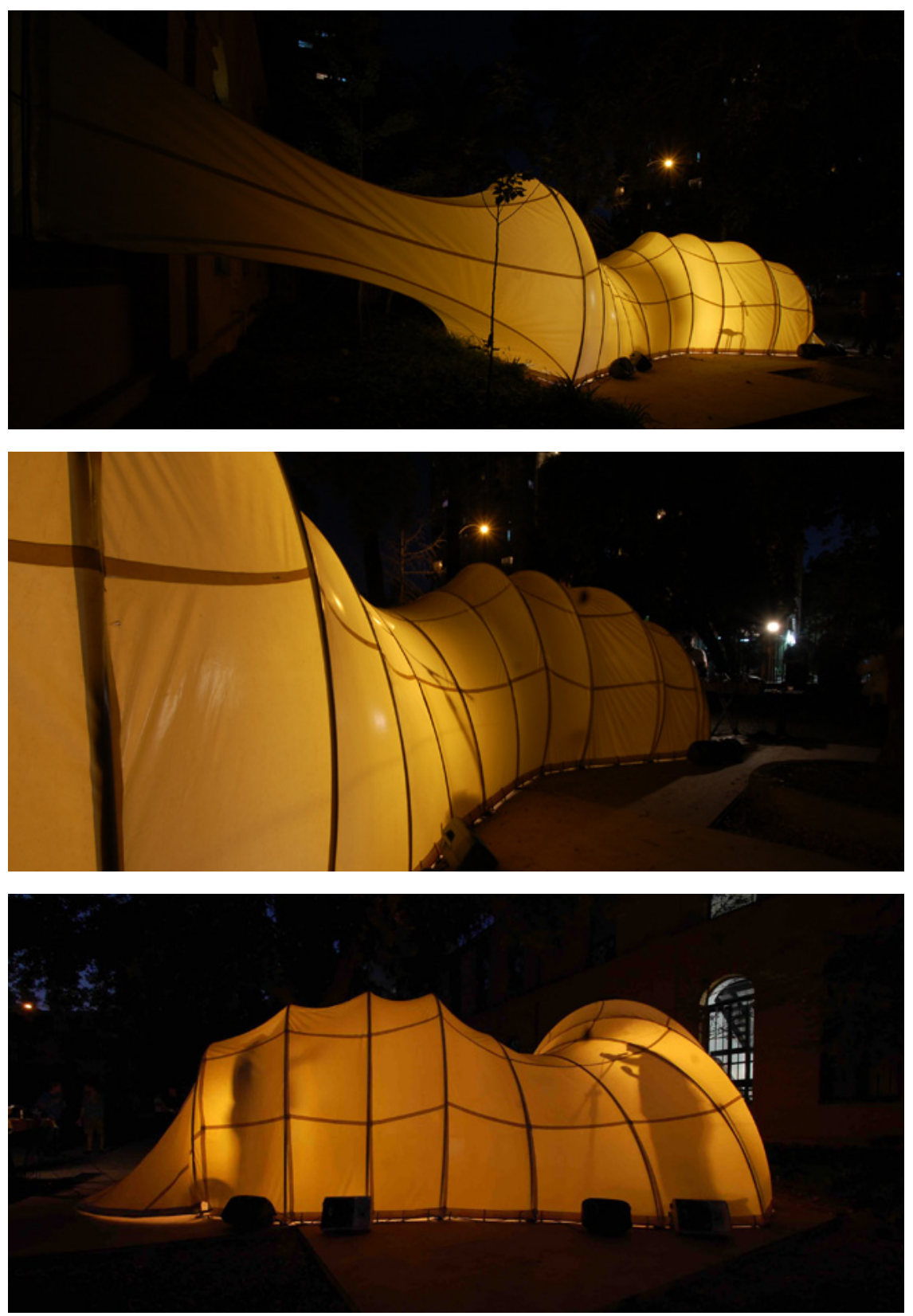

Arquitectura oral, performance, Martín Gubbins, 2016.

Informe, vistas nocturnas de cápsula en FAU/U. de Chile, 2016.

Fotografía ArqTex. 


\section{Aciclopedia}

Cuando Diderot y d'Alembert emprendieron la idea de una hipercrítica enciclopedia, tuvieron en cuenta no sólo el Novum Organum (1620) de Bacon, sino también las taxonomías de la llustración científico-burguesa y los valores de igualdad y derecho que dejarían de manifiesto algo más que un contrapunto a las artes liberales; esto es, la valoración de las artes mecánicas o serviles tan denostadas por los hombres libres bajo la máxima medievalista Trivium et Quadrivium ${ }^{9}$. En ese aspecto, no es menospreciable el trabajo que De Gua habría realizado de forma previa a la materialización de L'Encyclopédie (1751-1772); editorialidad mecánica que no sólo se desmarcó del influjo fundacional de la Cyclopaedia británica (1728), referente predilecto de Le Breton, sino que, además y a pesar de la disputa inconciliable con su censor, incidió en el examen crítico de las entradas que gobernarían el índice alfabético del futuro diccionario razonado (Darnton, 2014).

Quizá no haga falta señalar la importancia de dichas alusiones al enciclopedismo más ilustrado, del cual hoy hemos heredado conspicuos formatos de lectura total: enciclopedias digitales, thesaurus universales, archivos de metadatos, etc. Sin embargo, pese al reconocimiento que estos sistemas conllevan, el factor que los une, sobre todo, es la esencia de su carácter canónico. Ir más allá del canon significa, incluso en la tradición ilustrada, ir detrás de las huellas que enlazan razón y crítica, aun cuando ambas por separado solamente permitan afirmar todavía más el canon de un saber. Dicho de otro modo, la razón y la crítica están, según la enseñanza kantiana, afianzadas en el juicio de que la valoración de la forma no puede ser comprendida simplemente por lo visto y que, por el contrario, sólo puede ser informada por medio de su razón crítica. Ahora bien, razón y canon están unidos, del mismo modo que el más allá del canon está emparentado con la crítica. Sin embargo, la crítica también se podría encontrar en un límite, es decir, la enciclopedia es crítica en sí debido a su propia tecnología letrada, esto es, al interregno que ocupa justo en el límite del canon, en el más allá y el más acá de la ley (Thayer, 2010: 55), pero también sería acrítica si negara el germen editorial de su propia fórmula capitalista-popular, aquella que le valió ser una perfecta mercancía de intercambio competitivo en medio de los procesos de emancipación del conocimiento dieciochesco (Darnton, 2006: 612).

Así, el más allá del canon constituyó, justamente, una premisa crítica sobre la cual se situó una especie de frontera editorial, en cuyo horizonte estaba la dimen-

\footnotetext{
9 Referimos a la agrupación de las siete artes liberales que, en el siglo VI, se transformaron en un cuerpo enciclopédico identificado por Cassiodoro con la educación de las letras divinas y humanas, en posición a las artes serviles vinculadas con los oficios destinadas a los esclavos. En la Alta Edad Media las artes liberales se consolidaron en dos grupos: Trivium y Quadrivium. El primer grupo comprendía las disciplinas relacionadas con la elocuencia: gramática, retórica y dialéctica; mientras que el segundo agrupaba las disciplinas asociadas con las matemáticas: aritmética, música, geometría y astronomía Una referencia general en Eco (2015).
} 
sión acéfala de aquello que, gobernado por el secreto de un círculo académico -dicho en un sentido abyecto asociado al enciclopedismo de Acéphale (1936)-, no podía constituirse más que por el descabezamiento de toda forma. Para el caso, lo informe constituye la forma de aquello que no logra separar la cabeza del cuerpo, la gusaneidad; por tanto, su narrativa se asume como una razón crítica incompleta, como la negación de la totalidad, y simplemente deja un compendio de palabras sueltas sin cabeza rectora.

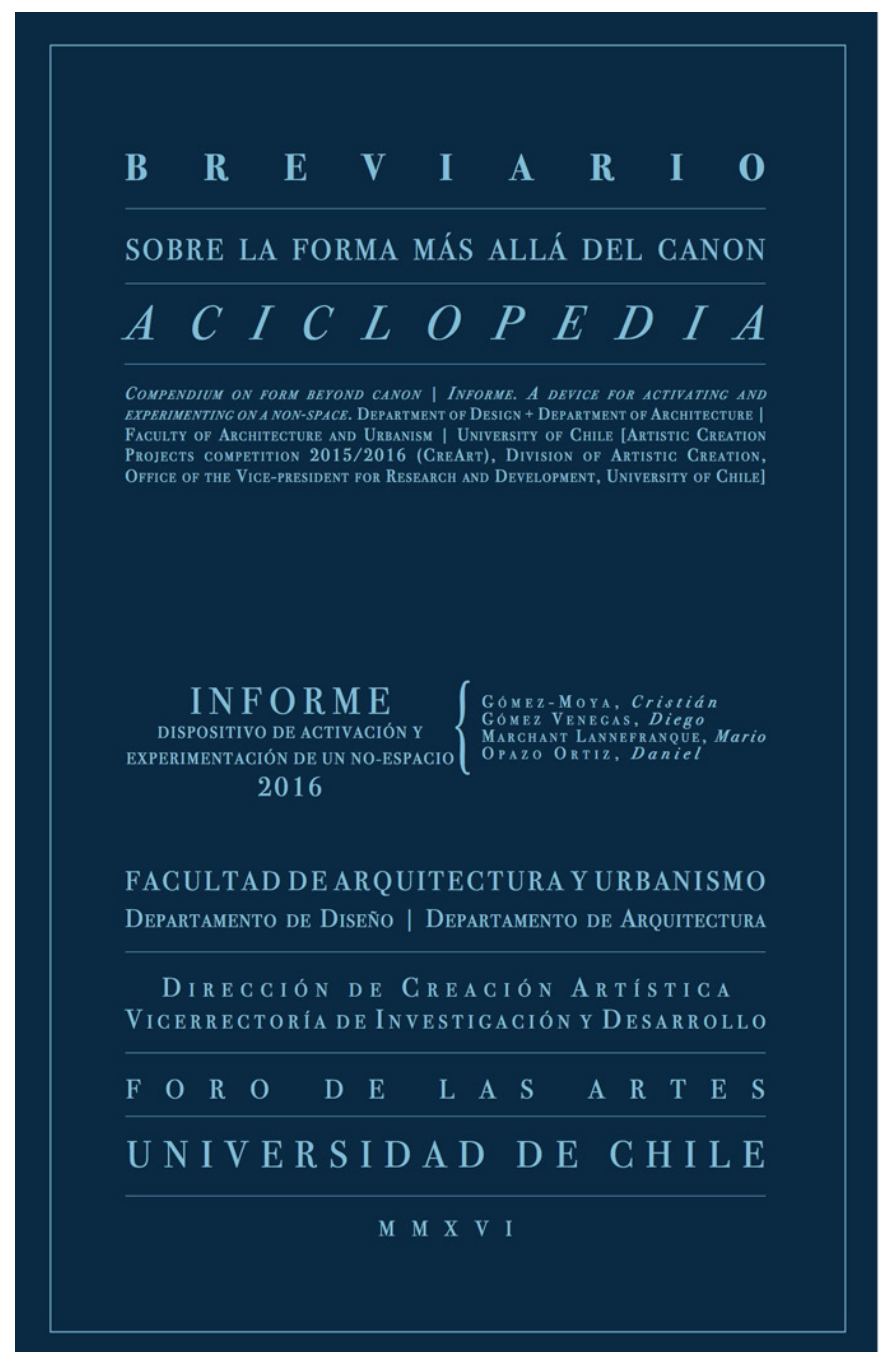

Portada libro Aciclopedia. Breviario sobre la forma más allá del canon (2016). 
Detengámonos por un momento en el breve exergo titulado "La América desaparecida" (1928), en el que Bataille analiza el sacrificio y la muerte del imperio azteca -incluyendo en ese lugar ilusorio al resto de los países americanos-, para explicar el tormento que sufrían estos pueblos y su renuncia ante los conquistadores con una muerte súbita: "Así concebían su extraña agitación. Extraña y precaria, puesto que murieron tan bruscamente como un insecto que uno aplasta" (BataiIle, 2010: 82). Su autor atribuía esta particular forma de colapso a una medida de resistencia que las culturas precolombianas encontraron para "enfrentar" y afirmar su imperio ante la violencia furibunda infligida por los conquistadores. Entendida muchas veces como una paradójica expresión de soberanía ${ }^{10}$, dicha inmolación auguraba una forma de antropofagia suicida en términos de no sucumbir a la lengua del otro.

No será la última vez que el bibliotecario francés se vea conmovido por un hecho de sangre espectacular. Años después, en 1961, Bataille quedaría impresionado con las fotografías del martirio de Fu-zhu-li, una horrorosa práctica imperial desarrollada en China hasta comienzos del siglo $X X^{11}$, en la que se destroza a un sujeto vivo, quien, sostenido en sus vasos sanguíneos, presencia su propio descuartizamiento. Pero lo que le remecía a Bataille no era lo espeluznante de la escena, sino la conciencia del verse a sí mismo sufriendo tamaño dolor (su "pequeña muerte"). Por lo tanto, el acento recaía sobre el hecho de ver, ver aquello que el ojo mismo podía arrojar fuera de sí en tanto ojo; entonces, verse a sí mismo desde afuera, pero con sus propios ojos. Extraordinaria condición que también se manifestaba en un sujeto capaz de enuclear su propio órgano -palabra incómoda, pero determinante en la narrativa batailleana-, es decir, quitar el globo ocular: "rechazó al capellán pero se enucleó y le hizo el regalo jovial del ojo así arrancado, porque ese ojo era de vidrio" (Bataille, 2003: 39). No es insignificante la crónica ocular que fabulaba el autor para hacer manifiesto su asombro hacia el instante en que el sujeto sucumbe bajo su propia mirada. Mezcla de espanto y excitación es lo que Bataille, finalmente, terminaría parafraseando, a través del cronista Robert L. Stevenson, como la "golosina caníbal" (Assandri, 2007)12; denominación referida no sólo a la perturbación que pudiese ocasionar ser conscientes de un ojo que, aun fuera de su cuenca, nos sigue observando sino, además, a los trastornos posibles del ojo bajo el dictum del documento de mirada, del informe que nos enseña y también nos mira.

10 Un estudio relevante al respecto en Antelo (2008).

11 Conocida como Muerte por mil cortes, esta milenaria forma de suplicio resultó adecuada a Bataille para su documentación en Les Larmes d'Éros (1961) (Stoneman, 2013).

12 La expresión "golosina caníbal", tal como lo revela el propio Bataille, fue extraída del texto del escritor Robert Louis Stevenson, In the South Seas (1896). No es posible omitir el legado de Stevenson sobre los imaginarios antropofágicos producidos, principalmente, a través de sus novelas de viajes polinésicos bajo el protectorado británico a finales del siglo XVIII (Assandri, 2007). 
En efecto, la relación entre el ojo enucleado y la posibilidad de un documento crítico estaba en el fondo literario de un pensamiento por lo informe, así como en el desacato que fungía el canon de un saber total compactado bajo aquel delirante primer índice de abreviatura léxica, Documents (1929-1930). Ciertamente, diremos que la práctica de desmontar la universalidad de una enciclopedia -la promesa de su canon abarcador- no solamente ha tenido, en el caso batailleano, un sesgo crítico hacia el rol eurocentrado de comprenderlo todo en tanto paradigma de la emancipación de la ciudadanía, la igualdad universal y el rol soberano del saber ilustrado; también comparece en este civilizado saber la mustia huella de lo sanguinolento que encubre la letra decolorada del enciclopedismo: cultura y barbarie.

En el ambicioso ejercicio curatorial que Yve-Alain Bois y Rosalind Krauss ofrecieron bajo el título de Formless (1997), lo informe aparece constituido como una fuerza performativa, puesto que no únicamente desestabiliza el documento escrito, en tanto se construye sobre la dimensión de lo que Bataille identificaba como "heterología" y sobre los arcaísmos de todo asunto mitológico, sino especialmente porque convulsiona las bases del academicismo: "Documents' dictionary remains one of the most effective of Bataille's acts of sabotage against the academic world and the spirit of system" (Bois, 1997: 16). Quizá fue ese el canibalismo paródico de aquel dictionnaire critique -alimentarse con la lengua académica del otro sin serlo-, más aún cuando se trató de un compendio de palabras que no esperaban tener una razón gramática o taxonómica ni mucho menos lograr algo perecedero y en ningún caso la totalidad.

\section{Publicación}

¿Cómo comparece este imaginario inverso entre enciclopedismo y ojo caníbal, en una lectura sobre el ejercicio editorial que implica pensar el canon de la forma? Partamos de un epítome que, teniendo como antecedente la literatura occidentalizada de la forma, se consume a sí mismo bajo el propio canon de la academia. Y partamos recordando, además, que en las antípodas de una enciclopedia se encuentra lo que el clero litúrgico, especialmente marcado por el Concilio de Trento (1545-1563), hizo prevalecer como escritura -entre la Sola Scriptura y las Traditiones-, lo que finalmente daría cuenta de la norma canónica por medio de un breviario.

Con todo, la potencia del breviario litúrgico fue una materia contrarrestada por la crítica de las letras, esto es, lo que en la literatura laica sigue siendo el resumen, la palabra abreviada o, en definitiva, el desglose de una serie de categorías filosóficas que establecen el orden de una grafía en el lenguaje. De ahí, entonces, que, 
bajo la ficción de un metalenguaje, la publicación del Breviario más allá del canon de la forma constituyera un ejercicio fallido de antemano sobre el problema inabarcable que concita la propia forma. A saber, dicho breviario denotó un asunto aún más contradictorio en su efecto de completitud, pues estuvo precedido de la noción Aciclopedia en su título. Una a-ciclopedia es, desde luego, el camino menos afortunado para emprender un breviario, puesto que es una forma que no informa, más bien niega lo que contiene. Es decir, bajo el título Aciclopedia se encuentra el léxico ficticio de una promesa de abarcar lo que está más allá del canon y, además, de inducir el acontecimiento acéfalo de su enseñanza, incluso. Ahora bien, la carencia de cabeza está tanto en la enciclopedia como en el círculo de aprendizaje, es decir, si la sustracción "pedia" es educación (paideia) y, en este caso, dentro (en) de un círculo (kyklos), entonces el prefijo a es la negación anómica no sólo de lo que está dentro, puesto que no informa del interior, sino que además niega la posibilidad de educar bajo la práctica de la encyclio paedia que profesara Quintiliano en su afamada Institutio Oratoria (circa 95 d. C.).

Si la Aciclopedia consistió, finalmente, en neutralizar su propio principio historiográfico (el enciclopedismo occidental) ${ }^{13}$ por medio de una forma de breviario laico, es porque en ella se expresaron la parvedad y la síntesis de la escritura ( $\mathrm{gra}$ fía) y la imagen (morpha), en un cruce de lenguas que, sin mediar más burocracia que lo político de la forma, dieron por válido contribuir desde su propio quehacer a una zona de incertidumbre. Esta zona intersticial, que requería (des)conocer los principios maestros de las disciplinas policiales en muchos casos, sería marcada por la gramática del alfabeto y por una letra capitular aleatoriamente consignada como resto (Castillo, 2016: 40). A partir de esta primera solicitud o pie forzado, los/as autores/as convocados/as a participar de la publicación abordaron la tarea de articular una noción o imagen con diferentes estrategias que dieran cuenta de ese más allá: i) en algunos casos, reutilizando el significado hallado en la propia consulta de la palabra, haciendo uso de su denotación al modo de un ready-made enciclopédico; ii) en otros, aprovechando un espacio que, en apretada síntesis, permitiera expresar quizá con mayor vértigo lo que su propia tenacidad académica no ha logrado más que contener; iii) o bien dando cuenta de una visualidad que oscilaba entre la episteme letrada y la ficción que parece alimentarse, ciertamente, de las sombras y los residuos de todo aquello que el archivo enciclopédico ha desdeñado.

13 El problema del enciclopedismo occidental nos lleva a preguntar si cabe acaso pensar la enciclopedia más allá de la historia escrita de la humanidad y más acá de la historia de las máquinas. Dicho puente in extremis, no puede sino advertirnos del intríngulis que subyace a las siguientes interrogantes: ¿es posible comprender la historia de la escritura como una historia de las máquinas? ¿Es la enciclopedia, actualmente, una máquina posthumana? (Kittler, 1999, 2017). 
En cualquiera de estos casos, lo que los unía era la anomia provocada por un saber que, a pesar de la soberanía del juicio enciclopédico, podía oficiar de suspenso académico. Una especie de iconoclastia formal parecía necesaria, pues las proposiciones buscaban provocar la imposible comunicación del texto y la carencia de identidad -informativa, icónica- reconocible incluso en una simple imagen. De ahí, entonces, que las nociones se transformaran en formas en sí mismas a pesar de su grafía: Anarchive (Daniel G. Andújar); Bitterness (Joan Ockman); Comunismo (Miguel Valderrama); Desenvolver (Pablo Núñez Gutiérrez); Entre (Willy Thayer); Figura (Hugo Rivera-Scott); Gaza [Portrait of] (Jonathan Cecil); Heliotropismo (Alejandra Castillo); [natural] Ismo (Paloma Villalobos); Jota (André Menard); Kaufmann's Autonomy (Nika Grabar); Loop [drumCircle] (Christian Oyarzún); Máscara (Gabriela Rivera); Nodal [nudo] (Roque Farrán); [Ñ] Eñe (Javier Jaimovich); Oscilación (Luis Guerra); Patrón (María Hurtado de Mendoza); Quimera (Esther Gabara); Ruptura (Mauricio Barría); Stranger (Brandon LaBelle); Transgresión (Sergio Rojas); Urgencia (Marina Otero Verzier); Vigesimotercera (Felipe Cussen); Windows (Daniel Cruz); [X] Hacia la forma 'X' (Iván Flores A.); Yapa (María Berríos); Zona (Marcelo Becerra).
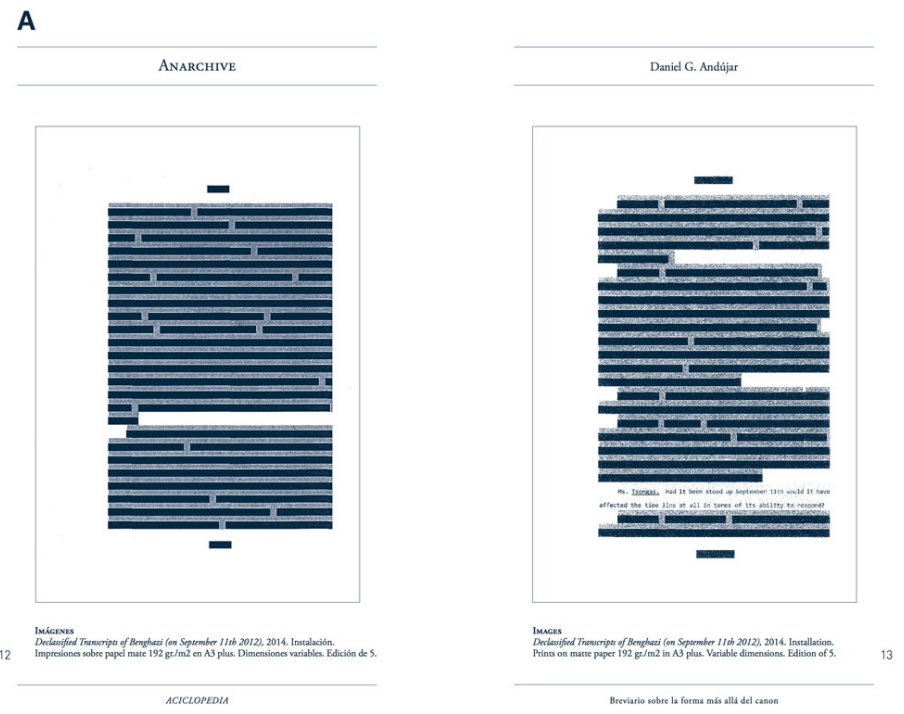

"Anarchive", Daniel G. Andújar. Páginas interiores Aciclopedia (2016). 


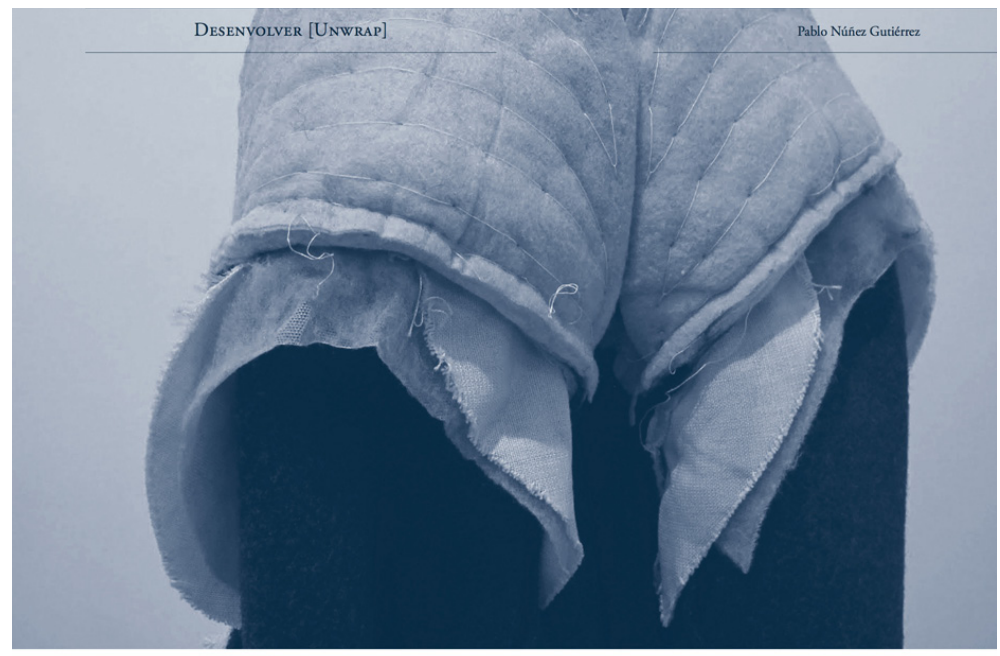

"Desenvolver" Pablo Núñez Gutiérrez. Páginas interiores Aciclopedia (2016).

$\mathbf{F}$

FigurA

LA PALABRA FORMA DESIGNA (ES) UN CONCEPTO que implica esencialmente la apariencia de toda existencia: la de los seres vivos que hacemos parte así como la de las cosas que pueblan nuestro mundo y también el universo. La forma por lo tanto da expresión al aspecto visible del mundo natural, tal como al de las cosas artificiales que son obra de un ser humano, quien imprime en ellas su "voluntad de forma", la que se expresa en su configuración como totalidad, unidad y estructura. Sin embargo, esta condición, que pareciera ser siempre la expresión externa de los seres y de las cosas, constituye en ese sentido una propiedad de la visibilidad de todo ello, la que según la comprensión más extendida lo caracteriza comúnmente. Pero lo que vemos no es sino su figura, entidad que, identificada básicamente como un contorno con algunos otros atributos, son lo que permite incluso su representación. Exactamente entonces "la forma" de lo que vemos como realidad es su figura, la que posee en este sentido un detrás, más bien oculto, que es lo que deberíamos llamar en propiedad, o con mayor rigor, su forma, pues ella implica un concepto dimensional que corresponde a una relación entre partes, conformado por la materialidad, que da a las cosas su condición objetiva.

Hugo Rivera-Scott

A esta pertenecen también algunos otros atributos que la configuran o componen, como son su color, textura y cstructura, medios que agregan información más compleja de percibir; todos ellos le otorgan sus cualidades particulares e integran en lo que es acaso su atributo principal: el significado. 


\section{Praxis}

Habida cuenta de los recursos teóricos, nos detendremos finalmente en la importancia que ambos dispositivos han tenido en su puesta en práctica, ya que la dimensión crítica y reflexiva sobre la cuestión de la forma permitió mucho más que una simple preocupación documental sometida al cruce de referencias. Primordialmente, el proyecto se propuso desde un inicio estimular diversas voces y cuerpos para ser parte de la activación de este no-espacio. Para ello, consideramos esa zona dividida entre el problema físico asociado con la cuestión morfológica, por un lado, y el espacio editorial concebido también como una zona paratextual, por el otro.

En el primer aspecto, relativo al espacio morfológico del objeto, el trabajo colaborativo entre arquitectos, artistas y diseñadores, profesores y estudiantes sirvió para instalar una dimensión democrática sobre la razón del diseño espacial, es decir, para pensar el diseño desde un reconocimiento por lo común, lugar en donde los distintos saberes disciplinares podían tributar de manera amplia, pero también contradictoria a la cuestión morfológica, conflictuando incluso el saber de las propias disciplinas. ¿De qué modo se pudo tensionar entonces este saber de las disciplinas? Básicamente, a través de una discusión colectiva entre los miembros del equipo de creadores y curadores y los propios invitados, quienes interrogaron la negatividad del espacio, así como su función prediseñada.

En un inicio, se planteó que la cápsula Informe debía pensarse desde la metáfora parasitaria: absorber energía para lograr su propósito orgánico. Si bien la energía se extrajo materialmente (fuente de electricidad, conectividad inalámbrica, ventilación, anclaje al edificio, instalación sobre suelo nivelado, etc.), también presentó una dimensión escópica centrada en la mirada entre interior-exterior. Se diseñó la cápsula con un apéndice en trompa, cuyas terminaciones consistieron en una mirilla desde el hall de decanato y su expansión hacia el interior de la propia cápsula. La relación de figura y fondo fluctuaba, por tanto, en un cruce de miradas mediadas por la gusaneidad de la forma. Dicho de otro modo, el propio diseño intersticial de la cápsula Informe estuvo centrado menos en su forma visible que en el tubo comunicante entre interior y exterior.

Por otro lado, subrayemos que esta relación espacial no se propuso en términos de diseños formales únicamente, pues también se sostuvo en una espesa práctica burocrática. Es por ello que lo informe jugaba una doble función referencial: lo estético-técnico y lo oficial-administrativo. Respecto de lo estético-técnico, hizo falta indagar en los conceptos morfológicos que hemos descrito, pero también alcanzar un grado de tecnicismo respecto de la forma, en virtud de las materialidades utilizadas y, particularmente, en cuanto a la viabilidad de la membrana sobre un esqueleto estructural autosoportante y al conflicto climático interior/ exterior de la 
cápsula. En términos de lo oficial-administrativo, se han señalado las dificultades comunicacionales surgidas en torno a un trabajo que negaba la funcionalidad del espacio y de su propia forma, así como el ejercicio administrativo de la igualdad en base a la autoridad de quien firma. Ciertamente, el ejercicio resultó indomable en muchos aspectos, ralentizándose los procesos y las planificaciones del programa curatorial. Sin embargo, y más allá de los inconvenientes de la burocracia, cabe también sostener el rol que cumplió la propia acumulación de cartas de solicitud y respuesta, extensos requerimientos y condiciones para la ejecución del dispositivo, cuyos opacos procedimientos, si bien hicieron vacilar la implementación del proyecto, también contribuyeron a robustecer su mismo sentido. Expresado de otra manera, el proyecto se consumó más allá de la morfología final instalada en el espacio de conflicto; su ejercicio crítico se plasmó principalmente a través de un cúmulo de cartas que materializaron y evidenciaron la noción de lo informe, precisamente, en su propio informe burocrático: una carpeta cuyo interior se completó con una serie de memorándums, cartas de solicitud, respuestas a dichas cartas, certificados, planos adjuntos, órdenes rechazadas, aprobaciones y desaprobaciones, etc.

Respecto del dispositivo editorial, la condición escritural de la Aciclopedia, puso en un pie forzado la necesidad de reducir los recursos gramaticales a una entrada única. Si bien los autores se entregaron al desafío impuesto por los editores, también se produjo una discusión previa respecto de un requerimiento a todas luces inusual. Citas, referencias, autorreferencias, extractos de textos, paráfrasis y una serie de estrategias retóricas surgieron para responder al encargo, tal como lo indicamos páginas atrás. Evitando la edición académica, finalmente las entradas fueron publicadas intentando mantener su estilo original y en ningún caso buscando la homologación científica. A pesar del espacio diagramático, definido ex profeso sobre una columna única y utilizando elementos de orden análogo a la L'Encyclopédie, su naturaleza editorial marcada por el alfabeto y la semántica buscó provocar la apariencia de un texto canónico, pero, asimismo, el extrañamiento del lector frente a los contenidos implícitos en su propio ejercicio de incongruencia entre escritura y significado, imagen y referente.

En suma, lejos de intentar una publicación al uso de una referencia de consulta, el texto se editó pensando en un "libro raro" -según lo cual una terminología de thesaurus podría verse tentada a clasificar. De otro modo, diríamos que su experiencia de búsqueda y clasificación, tanto dentro del orden bibliotecario institucional como del lector individual, se puso en abismo de su propia referencialidad; es decir, que siempre podía ser susceptible de una discusión taxonómica semejante a aquello que Foucault (1968), se sabe, recurriendo a un breve cuento de Borges, reclamaba como ese espacio de las heterotopías en que ciertas enciclopedias pertenecen a un tipo de pensamiento otro que, finalmente, es el límite del nuestro. 


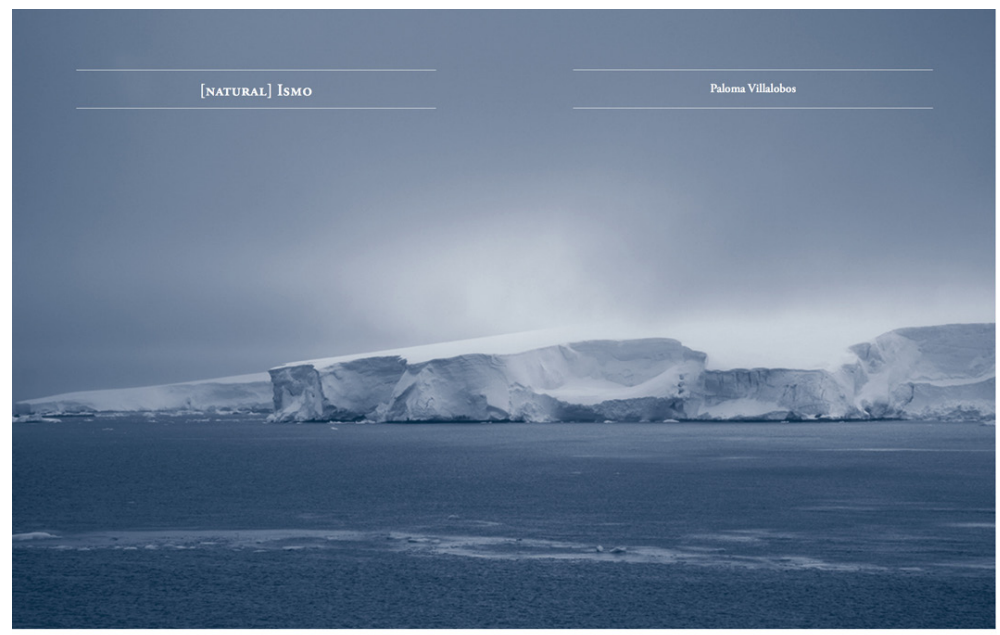

46

Imicesess

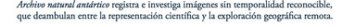

ACICLOPEDLA
IMAGES

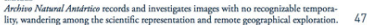

"[natural] Ismo", Paloma Villalobos.

Páginas interiores Aciclopedia (2016).

$J$

JoTA

JURAN LOS LINGÜISTAS QUE EN SU JUVENTUD LA lengua castiza no hacía de la jota el sonido gutural con que actualmente la arrastramos más o menos atrás del paladar. En sus inicios vibró en el extremo opuesto de la boca, más o menos cerca de los dientes, como sigue vibrando en las demás lenguas del mundo en que reconocemos su forma. $Y$ así como tras la misma forma de una letra se suceden $y$ penan distintas formas de la voz, la misma forma del sonido puede arrastrar los fantasmas de viejas formas de la letra, por ejemplo de un junco egipcio o de una manos fenicia. Visto así, estas letras son como los ecos de un junco y de una mano que alguna vez existió y que existiendo hizo que alguien la nombrara o la escribiera, es decir que la perpetuara en una forma. Sustraída a la irreductible materialidad del junco singular, la forma fue inscrita en otras materialidades, bocas, voces, papiros o tablas de arcilla, siempre materiales y siempre singulares. Yasí, vuelta jota espańola y medieval, es deci fricativa prealveolar y postpalatal, llegó en el siglo XVI a Reyno de Chile. Y allí se encontró con otras bocas, otras voces y otras lenguas. Y ocurrió que montada en el muy material lomo de ovejas y agujas espańolas y medievales, es decir de ovejas y agujas fricativas prealveolares y pospalatales, se encontró con el mapudungun, lengua que en ese momento compartía con el español medieval la
André Menar

ausencia de la jota moderna, es decir de la jota aproximante palatal que actualmente arrastramos cerca de la garganta. ¿¿Y qué pasó entonces? Pasó que así como un junco hizo un día entrar a la jota en la historia del alfabeto, una aguja y un par de ovejas hicieron entrar, no a la jota, sino que a la historicidad de la jota, al espectro de su ancestro medieval, en el mapudungun que se habla hoy día. Oveja se dice "ofisa" u "ofisha" (y no "oveka" u "ovika" como era de esperarse a partir de una jota moderna). Aguja se dice "akucha" (y no akuka). Y así como la arcilla sirvió de soporte o materia para la forma de un junco muy antiguo, es como si el mapudungun sirviera de arcilla para conservar el sonido de otra lengua, la forma -o el testimonio- de una jota muerta. 


\section{Post scriptum}

De un modo quizá que no desconoce la acción parasitaria de una energía mayor, situada ésta en el ámbito de lo academicista, estos ejercicios intersticiales (Barría, 2016: 82) se han propuesto como terrenos inciertos antes que como topos concluyentes. Queremos reconocer en ello que toda pregunta por la forma concierne a una incógnita que se pierde en su propia genealogía impura, aun cuando su paradigma parece gobernarse por ese clima de época en torno a la igualdad, el cual ejerce como poder de escritura sobre lo que informa.

Si todo texto es un tráfico de imágenes -y, al decir imágenes, únicamente exponemos residuos dejados por el enciclopedismo y lo construido como forma escrita-, es porque este proyecto ha pretendido eso, sencillamente: dejar restos de un posible intercambio, como la yapa que "es exceso puro, derroche y anti-deuda" (Berríos, 2016: 111); meditaciones activas sobre algo tan incierto como quizá urgente: pensar es el acto que deshace la forma, sería su paráfrasis batailleana.

Informe y Aciclopedia: dos dispositivos que se coluden en un coro de voces desusadas que no se gobiernan por una misma idea; su pensamiento es disímil y, por esa circunstancia, llevan a pensar no en el ejercicio de la disciplina como obediencia a través de la enseñanza (rei militaris scientia), sino como la indisciplina de aquello que también exige radicalizar su misma enseñanza. En el fondo de estos dispositivos, reposa la pregunta por el saber documental, sin duda, pero también sobre la democratización de las formas académicas.
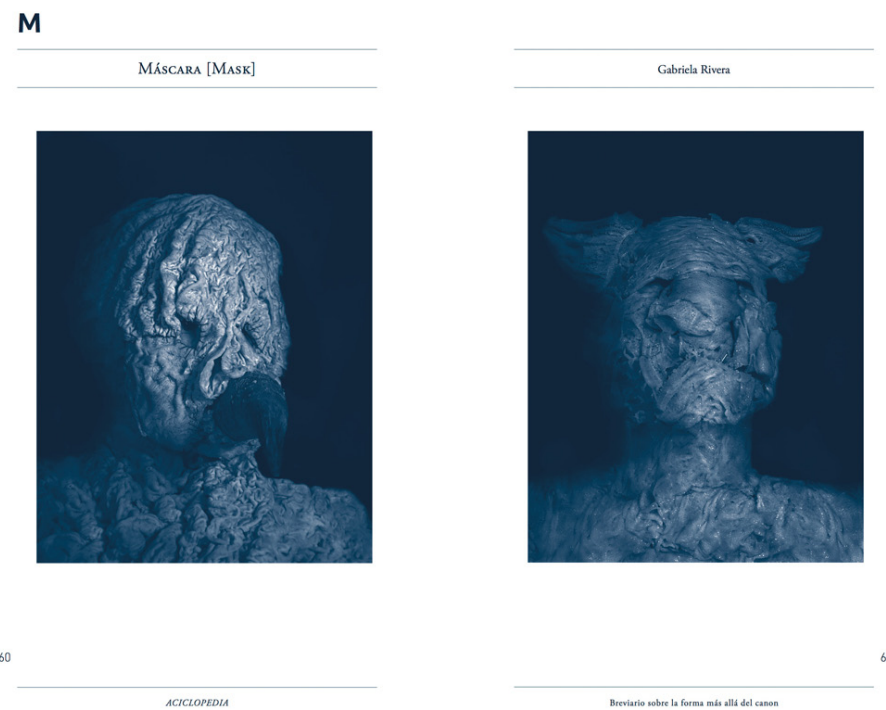

"Máscara", Gabriela Rivera.

Páginas interiores Aciclopedia (2016). 
Panambí n. 6 Valparaíso jun. 2018 ISSN 0719-630X. 5-29. DOI:10.22370/panambi.0.6.1131.

U

$\overline{\text { URGENCIA }}$

MENSAJES, NOTICIAS, ENVíos, ENCARGOS. $\mathrm{La}$ urgencia se ha expandido desde la condición de excepcionalidad hasta permear el espacio de lo rutinario; desde los contextos afectados por desastres naturales y conflictos armados, hasta el estado de cmergencia convertido en técnica general de gobierno.

Bailamos al ritmo de lo urgente, en la mayoría de los casos como estrategia de sup caso cor tisfacer la raper que dictan los reginenes cconómicos actuales. La urgencia, para muchos, también es rentable. Capitaliza el miedo a la incertidumbre, viene acompañada de la retórica de la resiliencia urbana, y en ocasiones del oportunismo de operaciones inmobiliarias, maniobras políicicas, $y$ aumento en gastos militares.

Algunos de los más sofisticados actos de diseño y estrategias para gestionar riesgos, escenarios de catástrofes, o ataques terroristas, son producto de la urgencia: diques de contención, sistemas de control biométrico en aeropuertos, prototipos de viviendas de cmeroencia para refugiados. Éstos circulan a través de las aulas de escuelas, las páginas de revistas especializadas y las salas de museos.

94

ACICLOIEDIA

$\overline{\text { Marina Otcro Verizer }}$

Lo urgente nos atrapa en un estado simultáneo de ansiedad y frenesí, en un sistema de valores que premia el movimiento, el cambio, la capacidad de adaptación, y transformación en respuesta a una aparente crisis sistémica, la reflexión convertida en un bien cscaso. Paradójicamente, algunas acciones destinadas a nuestra protección, como parte de las políicicas de urgencia, debilitan aquello que posibilita nuestra vida en común y nuestra capacid política contriburen a for política; contribuyen a formalizar $y$ normalizar la preca-
riedad, $y$ a sustentar su permanencia.

1 En el siglo pasado, y sobre todo en cl actual, hemos sido tes-
tigos de lo que Giorgio Agamben menciona cn su libro, Essado tigos dc lo que Giorgio Agamben menciona en su libro, Essado radigma de la seguridad como técnica normal de gobierno". Agamben, Giorgio, Estado de excepcion, trad. Flavia Costa e Ivana Costa (Buenos Aires: Adriana Hidalgo editora, 2005), p. 44. Como ejemplo de esta tendencia, en julio de 2016, Asamblea Nacional Francesa aprobaba ta prolongación del estahasta enero de 2017 , usando come agumento d la ro rogo de la amenaza terrorista.

\section{Z}

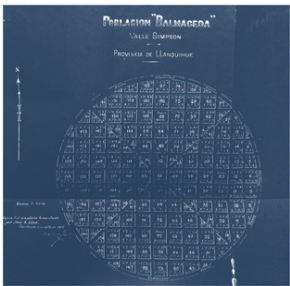

Imagen | Image
Disefo de planific

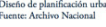

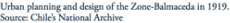

Marcelo Becerra
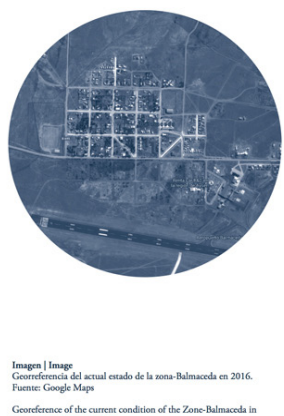

Ceoveffenence of the current co
2016. Sourte Googlc Maps 


\section{Referencias}

Antelo, R. (2008). Crítica Acéfala. Buenos Aires: Grumo.

Assandri, J. (2007). Entre Bataille y Lacan: ensayo sobre el ojo, golosina caníbal. Buenos Aires: Cuenco de Plata.

Augé, M. (2002). Los no lugares. Espacios del anonimato (1992). Barcelona: Gedisa.

Baitello Jr., N. (2017). La fotografía y el gusano. CANAL. Cuadernos de Estudios Visuales y Mediales, (1), 56-73.

Barría, M. (2016). Ruptura. En Gómez-Moya, C.; et al. Aciclopedia. Santiago: VID, Universidad de Chile, 82-85.

Bataille, G.; Henri, G.; Leiris, M. (1991). Documents (1929-1930). París: Jean-Michel Place.

Bataille, G.; Caillois, R.; Klossowski, P.; Masson, A.; et al. (2013). ACÉPHALE (19361939) (1936-1939). Buenos Aires: Caja Negra.

Bataille, G. (2010). La América desaparecida. En Álvarez, E.; Medina, C. El espectro rojo (1928). Madrid: CA2M Centro de Arte Dos de Mayo, 80-82.

(2003). Ojo. La conjuración sagrada. Ensayos 1929-1939. Buenos Aires: Adriana Hidalgo, 37-39.

(1997). Las lágrimas de Eros (1961). Barcelona: Tusquets.

Berríos, M. (2016). Yapa. En Gómez-Moya, C.; et. al. Aciclopedia. Santiago: VID, Universidad de Chile, 110-113.

Bois, Y.-A.; Krauss, R. (1997). Formless. A User's Guide. New York: Zone Books.

Castillo, A. (2016). Heliotropismo. En Gómez-Moya, C.; et. al. Aciclopedia. Santiago: VID, Universidad de Chile, 40-43.

Colomina, B.; Wigley, M. (eds.) (2016). Are We Human? Estambul: 3rd Istanbul Design Biennial, Istanbul Foundation for Culture and Arts.

Colomina, B.; Wigley, M. (2016). Are We Human? Notes on an Archeology of Design. Estambul: 3rd Istanbul Design Biennial, Istanbul Foundation for Culture and Arts, Lars Müller Publishers.

Darnton, R. (2006). El negocio de la ilustración. Historia editorial de la Encyclopédie, 1775-1800 (1979). México: FCE.

(2014). Censores trabajando. De cómo los Estados dieron forma a la literatura (2014). México: FCE.

Eco, U. (coord.) (2015). La Edad Media I. Bárbaros, cristianos y musulmanes. México: FCE.

Flores, I. (2016). X. En Gómez-Moya, C.; et. al. Aciclopedia. Santiago: VID, Universidad de Chile, 106-109. 
Foucault, M. (1968). Las palabras y las cosas. Una arqueología de las ciencias humanas (1966). Buenos Aires: Siglo XXI.

Gómez-Moya, C.; Gómez V., D.; Marchant L., M.; Opazo O., D. (eds.) (2016). Aciclopedia. Breviario sobre la forma más allá del canon. Santiago: VID, Universidad de Chile.

Grafton, A. (2015). Los orígenes trágicos de la erudición (1998). México: FCE.

Hirsch, N., Vidokle, A., eds. (2016-2017). Superhumanity. New York: E-FLUX. Recuperado de: http://www.e-flux.com/architecture/superhumanity/.

Kittler, F. (1999). Gramophone, Film, Typewriter. Stanford, CA: Stanford University. (2017). El mundo de lo simbólico - un mundo de las máquinas. CANAL. Cuadernos de Estudios Visuales y Mediales, (1), 122-157.

Latour, B.; Weibel, P. (eds.) (2005). Making Things Public. Atmospheres of Democracy. Cambridge, MA: The MIT.

Rancière, J. (2000). Política, identificación y subjetivación. En Arditi, B. (ed.). El reverso de la diferencia. Identidad y política. Caracas: Nueva Sociedad, 145152.

(2006). Política, Policía, Democracia. Santiago: LOM.

(1994). En los bordes de lo político (1990). Santiago: Universitaria.

Spieker, S. (2008). The Big Archive. Art from Bureaucracy. Cambridge, MA: The MIT.

Stevenson, R. L. (2013). En los mares del sur (viajes y aventuras) (1896). Madrid: Valdemar.

Stoneman, R. (2013). Such Cruelty. En Seeing is Believing: The Politics of the Visual. London: Black Dog Publishing, 34-36.

Thayer, W. (2016). Entre. En Gómez-Moya, C.; et. al. Aciclopedia. Santiago: VID, Universidad de Chile, 26-29.

Vesalius, A. (1543). De Humani Corporis Fabrica. Recuperado de http://vesalius. northwestern.edu/. 